\title{
How to evaluate the risks of work equipment and installations for health and safety? Research and activities of the German Committee for Plant Safety and consequences for regulation
}

\author{
Pieper R $\mathrm{a}^{\mathrm{a}, \mathrm{bl}}$ \\ a Institute of Occupational Health, Safety and Ergonomics (ASER), Corneliusstrasse 31, D-42329 Wuppertal, \\ Germany \\ ${ }^{b}$ Chairman of the project group "Special inspections for work equipment" of the German Committee for Plant \\ Safety
}

\begin{abstract}
Work equipment and installations with a high risk for health and safety of employees should be paid a special attention. The German Product Safety Act, which is aimed to manufacturers or distributors in order to protect consumers, maintains a conclusive catalogue of these so-called "installations in need of monitoring" fixing the work equipment and installations for which such special inspections can be demanded. This catalogue has remained unchanged for decades and has been transformed nearly unmodified into the Plant Safety Ordinance. Currently, there is a discussion about this catalogue in Germany. A major point of concern is the definition and the significance of "especially" dangerous work equipment and installations. Two recent research projects are dealing with the problem how to define "especially".
\end{abstract}

Keywords: work equipment, installations, risk assessment, general inspections, work safety, Product Safety Act

\section{Introduction}

Work equipment and installations with a high risk for health and safety of employees should be paid a special attention.

In 1989 the European Union released the Council Directive 89/655/EEC concerning the minimum safety and health requirements for the use of work equipment by workers at work. This directive was implemented in the German legislation with the introduction of the "Arbeitsmittelbenutzungsverordnung - AMBV)" in 1997, which was replaced in 2002 by the "Plant Safety Ordinance" (Betriebssicherheitsverordnung - BetrSichV) [1].

\footnotetext{
${ }^{1}$ Corresponding author: rpieper@uni-wuppertal.de
}

The Plant Safety Ordinance includes not only general obligations concerning the use of work equipment (risk assessment, general inspections, ergonomic aspects) but also special inspections of "installations in need of monitoring” (in German: "(überwachungsbedürftige) Ü-Anlagen”) by qualified individuals or inspection bodies (authorized inspection bodies).

The German Product Safety Act, which is aimed to manufacturers or distributors in order to protect consumers, maintains a conclusive catalogue of these socalled "installations in need of monitoring" fixing the work equipment and installations for which such special inspections can be demanded. This catalogue has remained unchanged for decades and has been trans- 
formed nearly unmodified into the Plant Safety Ordinance.

\section{Practice innovation}

Within the last years, a nationwide discussion upraised about this catalogue. Because of the dynamic technical development within the last years and because of some uncertainties about the selection of installations in this catalogue in particular, a revision and update of the catalogue and the inspection requirements seems to be necessary. In the beginning of 2011, the German Ministry of Labour and Social Affairs (Bundesministerium für Arbeit und Soziales BMAS) started the revision of the BetrSichV. To execute the revision, the German Committee for Plant Safety (Ausschuss für Betriebssicherheit ABS) was commissioned to advice the BMAS. The ABS committee includes experts of all relevant groups (state authorities, Accidental Insurance Associations, employers and employees, scientists). One of the most important and influential results of the activities of this committee are the development of technical rules in order to help to fulfill the regulations of the Plant Safety Ordinance which is directed to the employers to improve the safety and health of their employees at work.

\section{Results}

The main area of concern was to determine the significance of "especially" dangerous work equipment and installations. This work equipment requires special measures for the sustainable improvement of system safety. Two recent research projects ([2], [3]) are dealing with the problem how to define "especially". Is it possible to determine thresholds, which differentiate "especially dangerous" from "less dangerous"?

Based on these two evaluations of the existing regulation, two approaches that include strategies to determine relevant criteria have been developed.

In the discussions between researchers and experts in context of the project [2] it was revealed that a consideration of risk is inevitable. The approach of the catalogue of "installations in need of monitoring" is based essentially on an implicit risk assessment.

The main result of the first project [2] is a guideline for experts. This guideline should be used as a checklist to discover whether work equip- ment/installations are "especially" dangerous. The steps of the guideline are the following:

- Step 1

Screening and pre-selection of the types of work equipment/installations, which have to be examined by using the methodology

- Step 2

Description and differentiation of the respective work equipment/type of installation within the spectrum

- Step 3

Selection of a system scenario (usually this should be work equipment or installations in typical operational conditions)

- Step 4

Assessment of relevant occurrences and description of associated chronological scenarios

- Step 5

Estimation of probability of occurrence

- Step 6

Assessment of potential bonuses (which reduces the occurrence probability)

- Step 7

Examination of other similar types of work equipment/installations in other typical operational conditions. Are there other (higher) risks?

To handle the number of possible "especially" dangerous installations, the further discussion was focused on cranes within a first step. This is not only because one can easily assume that the use of some types of cranes can be "especially" dangerous but also because cranes are not specially mentioned in the German "plant safety ordinance". Measures of health and safety of workers at work concerning the use of cranes are still part of the autonomous regulation of the Accidental Insurance Associations in Germany (as a part of the so called "Dual System" of $\mathrm{OSH})$. Due to the European regulation the impact of the autonomous regulation is getting lesser over the last decades. Regulation in OHS is focused on state laws and ordinances. The role of the accidental assurance associations on the field of prevention is focused on rules and guidance, on inspection and advising. The state activities and the autonomous activities are brought together within the "German OSH Strategy".

The following example on cranes (draft) describes the application of the guideline mentioned above (table 1). 
Table 1

Example (draft) of a chronological scenario: Failure of the supporting structure (e.g. caused by corrosion, material fatigue or wear, damage, inadequate maintenance (e.g. welding)), load, crash of crane or components, crash of crane operator or cab crashes and people get hit.

\begin{tabular}{|c|c|c|c|c|}
\hline $\begin{array}{l}\text { considered } \\
\text { factor }\end{array}$ & $\begin{array}{l}\text { probability of } \\
\text { occurrence } \\
\text { (PoO): } 10^{-\mathrm{X}}\end{array}$ & description of factor & $\begin{array}{l}\text { measures to reduce } \\
\text { the probability of oc- } \\
\text { currence }\end{array}$ & $\begin{array}{l}\text { PoO incl. } \\
\text { bonuses: } \\
10^{-\mathrm{X}}\end{array}$ \\
\hline $\begin{array}{l}\text { Probability of failure of com- } \\
\text { ponents }\end{array}$ & +4 & $\begin{array}{l}\text { High complexity with numer- } \\
\text { ous elements of the supporting } \\
\text { structure, medium safety level }\end{array}$ & $\begin{array}{l}\text { Examination of the support- } \\
\text { ing structure at regular inter- } \\
\text { vals by specially qualified } \\
\text { personnel }\end{array}$ & +5 \\
\hline $\begin{array}{l}\text { Abrasive wear / } \\
\text { material fatigue }\end{array}$ & -2 & $\begin{array}{l}\text { High wear due to working } \\
\text { conditions (environment), } \\
\text { damage (e.g. by operator er- } \\
\text { ror), fairly low mechanical } \\
\text { wear }\end{array}$ & & -2 \\
\hline Human reliability & $+0,3$ & Maintenance, e.g. welding & & 0,3 \\
\hline $\begin{array}{l}\text { Identify risks and prevent / } \\
\text { avoid }\end{array}$ & 0 & $\begin{array}{l}\text { Corrosion and damage caused } \\
\text { by crane operator (qualifica- } \\
\text { tion) is difficult to identify } \\
\text { (only obvious damage); risks } \\
\text { can be eliminated only with a } \\
\text { specific qualification }\end{array}$ & & 0 \\
\hline Exposition & 0 & $\begin{array}{l}\text { The crane operator is perma- } \\
\text { nently exposed. Avoidance of } \\
\text { hazardous situations is hardly } \\
\text { possible. Other workers (crane } \\
\text { slinger, rigger) and others } \\
\text { usually remain in the danger } \\
\text { zone frequently or permanent- } \\
\text { ly. The average probability of } \\
\text { being hit is medium. }\end{array}$ & $\begin{array}{l}\text { Crane operators (including } \\
\text { those with wireless control- } \\
\text { ler), slingers/riggers and other } \\
\text { employees involved often } \\
\text { remain constantly in the dan- } \\
\text { ger zones of the crane. Rea- } \\
\text { son: The crane operator is } \\
\text { included in the normal way of } \\
\text { working; he is often a worker, } \\
\text { a crane operator and a slin- } \\
\text { ger/rigger in the same time. } \\
\text { Operating a crane with re- } \\
\text { mote control leads to a lack of } \\
\text { attentive feeling for the crane, } \\
\text { he is more willing to take } \\
\text { risks. }\end{array}$ & 0 \\
\hline Maintenance & 0 & Measures to maintain safety & $\begin{array}{l}\text { Preventive maintenance: } \\
\text { periodic inspection by partic- } \\
\text { ularly qualified people and } \\
\text { early corrective maintenance }\end{array}$ & +1 \\
\hline $\begin{array}{l}\text { probability of } \\
\text { occurrence without } \\
\text { bonuses: }\end{array}$ & $10^{-2,3}$ & & $\begin{array}{l}\text { probability of } \\
\text { occurrence with } \\
\text { bonuses: }\end{array}$ & $10^{-4,3}$ \\
\hline
\end{tabular}

\section{Discussion}

A transparent risk assessment demands a wide risk communication. A further criterion is the extent to which risk can be influenced by expert inspections. The great effort and expense involved in inspections by independent experts is only justifiable if the work equipment or installations involve a high risk which can be effectively reduced by such inspections. As a measure for the risk assessment it is necessary to establish a limit risk. Taking as an orientation reference values from adjacent areas and other states, the thresholds proposed for the limit risk were the death of a worker or a number of workers and for the occurrence probability $10^{-5}$. These threshold values were used in the trials. The trials revealed that the method could be applied efficiently and adequate to the problem for the question concerned. It also yields 
plausible, reliable and valid results. It provides a clear presentation of results, which appears to be a suitable means of assisting the Committee for Plant Safety in the establishment of an objective consensus and the expert formulation of inspection requirements.

\section{References}

[1] PIEPER, R. (2009): Arbeitsschutzrecht - Kommentar für Praxis, 4. Edition, ISBN: 978-3-766338-52-5.
Concerning cranes as an example, the outcomes of the projects give a base to evaluate the risks by using this work equipment. This is an important precondition to modify the regulation.

[2] BARTH, C. (2011): Ermittlung von Kriterien und Erkenntnissen zu Notwendigkeit, Art und Umfang sicherheitstechnischer Prüfungen von Arbeitsmitteln (einschließlich Anlagen), BMAS-Research Report Fb 410.

[3] HAUPTMANNS, U.; MARX, M. (2010): Kriterien für die Beurteilung von Gefährdungen durch technische Anlagen; Verlag VdTÜV, ISBN: 978-3-942718-34-9. 